\title{
Induction of Diabetes Abolishes the Antithrombotic Effect of Clopidogrel in Apolipoprotein E-Deficient Mice
}

\author{
A. Sugidachi ${ }^{1}$ \\ K. Ohno ${ }^{1}$ \\ J. A. Jakubowski \\ Y. Ito ${ }^{1}$ \\ A. Tomizawa ${ }^{1}$ \\ M. Mizuno ${ }^{1}$ \\ ${ }^{1}$ Rare Disease and LCM Laboratories, Daiichi Sankyo Co., Ltd., \\ Tokyo, Japan \\ 2 Lilly Research Laboratories, Eli Lilly and Company, Indianapolis, \\ Indiana, United States

\begin{abstract}
Address for correspondence Atsuhiro Sugidachi, PhD, Rare Disease and LCM Laboratories, Daiichi Sankyo Co., Ltd., 1-2-58 Hiromachi, Shinagawa-ku, Tokyo 140-8710, Japan
\end{abstract} \\ (e-mail: sugidachi.atsuhiro.r7@daiichisankyo.co.jp).
}

TH Open 2017;1:e92-e100.

\begin{abstract}
Keywords

- $\mathrm{P}_{2} \mathrm{Y}_{12}$

- clopidogrel

- diabetes mellitus

- platelets

- thrombosis

- apolipoprotein E-deficient mouse

- thrombin

Patients with acute coronary syndrome with diabetes mellitus (DM) exhibit an impaired platelet inhibitory response to clopidogrel which is only partially understood. DM was induced by the administration of streptozotocin (STZ) to 9-week-old mice. The antithrombotic effects of clopidogrel ( $10 \mathrm{mg} / \mathrm{kg} / \mathrm{d}$, orally $\times 5$ days) were determined using a $\mathrm{FeCl}_{3}$ induced thrombosis model employing wild-type (WT), apolipoprotein E (apoE)-deficient, and diabetic apoE-deficient mice at 21 weeks. Antiplatelet effects were determined using flow cytometry. The antithrombotic effects of clopidogrel were similar in WT and apoEdeficient mice but were attenuated in diabetic apoE-deficient mice with the percent inhibition of thrombus area $\left(\mu \mathrm{m}^{2}\right.$ ) by clopidogrel being $85.5 \%$ (WT mice), $75.0 \%$ (apoEdeficient mice), and $1.9 \%$ (diabetic apoE-deficient mice). The time to first occlusion and lumen stenosis also reflected a significant loss of the antithrombotic effects of clopidogrel in diabetic apoE-deficient mice. Ex vivo platelet activation, which was assessed using ADPinduced expression of activated glycoprotein IIb/IIla, was completely inhibited by clopidogrel in these three groups of mice. In contrast, the effect of clopidogrel on the ex vivo expression of platelet P-selectin induced by protease-activated receptor 4-activating peptide was diminished in diabetic apoE-deficient mice compared with that in WT and apoE-deficient mice. These data suggest that diabetic apoE-deficient mice may serve as a useful model to better understand the impaired responses to clopidogrel in patients with DM, which may partially reflect a reduction of the effect of clopidogrel on thrombininduced platelet activation.
\end{abstract}

\section{Introduction}

Dual-antiplatelet therapy using aspirin and an antagonist of the P2Y $_{12}$ ADP receptor is the first-line treatment for patients with acute coronary syndrome as well as for those undergoing percutaneous coronary intervention. ${ }^{1,2}$ Despite the development of $\mathrm{P}_{2} \mathrm{Y}_{12}$ antagonists with more predictable effects, such as prasugrel ${ }^{3-5}$ and ticagrelor, ${ }^{3,6,7}$ clopidogrel remains a widely used $\mathrm{P}_{2} \mathrm{Y}_{12}$ antagonist. ${ }^{8,9}$ However, the antiplatelet effect of clopidogrel is highly variable among individuals, ${ }^{10-13}$ and patients with higher platelet reactivity on clopidogrel

treatment are at higher risk of thrombotic events after percutaneous coronary intervention. ${ }^{14-16}$ Accordingly, delineating the mechanisms underlying the variable response to clopidogrel is clinically relevant and may provide insights into the reasons for treatment failure and inform selection of the three available oral $\mathrm{P}_{12}$ receptor antagonists administered to patients with acute coronary syndrome. ${ }^{17}$

Clopidogrel is a prodrug requiring hepatic conversion to an active metabolite (AM) that mediates the antiplatelet effect. Numerous pharmacokinetic(PK) and pharmacodynamic studies 
have shown that CYP2C19, a CYP450 isozyme, is important for generating clopidogrel's AM; moreover, common genetic polymorphisms that reduce the catalytic activity of CYP2C19 decrease AM production. ${ }^{18,19}$ However, the cause of the variability of the clopidogrel response is multifactorial, ${ }^{20-22}$ and diabetes mellitus (DM) is a major risk factor for a diminished clopidogrel response, independent of the CYP2C19 genotype. $^{20,21}$ Overall, patients with DM have an increased prevalence of low platelet inhibition following clopidogrel treatment and a two- to four-fold increased risk of cardiovascular events compared with patients without DM. ${ }^{23-27}$

While the cause of these characteristics has been attributed to systemic inflammation and insulin resistance, ${ }^{28}$ impaired inhibition of $\mathrm{P}_{2} \mathrm{Y}_{12}$-mediated platelet inhibition by clopidogrel is largely attributed to attenuation of clopidogrel's PK profile. ${ }^{29}$ Animal models for studying the impaired clopidogrel response have been employed; however, to the best of our knowledge, there are no reports of a wellestablished nonclinical model to study the diabetes-associated reduction of response to clopidogrel.

Streptozotocin (STZ)-treated apolipoprotein E (apoE)-deficient mice are widely used to model atherosclerosis with higher cardiovascular risks compared with apoE-deficient or STZ-treated diabetic mice. ${ }^{30-33}$ The $\mathrm{FeCl}_{3}$-induced thrombosis model is widely used as a standard method by thrombosis researchers. ${ }^{34,35}$ In this article, we used this thrombosis model to study the antithrombotic effects of clopidogrel in STZ-treated apoE-deficient mice (diabetic apoE-deficient mice) compared with its antithrombotic effects in wildtype (WT) and nondiabetic apoE-deficient mice (apoE-deficient mice). Further, we determined the antiplatelet effects of clopidogrel in these three groups of mice.

\section{Materials and Methods}

\section{Materials}

ADP, protease-activated receptor- 4 thrombin receptor activating peptide (PAR4 TRAP), and $\mathrm{FeCl}_{3}$ were purchased from Sigma-Aldrich (St. Louis, Missouri, United States). FITC-labeled rat anti-mouse GPIX (Xia.B4), PE-labeled rat anti-mouse GPIIb/IIIa (JON/A), and PE-labeled rat anti-mouse P-selectin (Wug.E9) antibodies were purchased from Emfret Analytics GmbH \& Co. KG (Eibelstadt, Germany). Clopidogrel bisulfate (clopidogrel) was purchased from Kemprotec Limited (Cumbria, United Kingdom). Gum arabic and STZ were purchased from Wako Pure Chemical Industries, Ltd. (Osaka, Japan) or Sigma-Aldrich. Receptor nomenclature follows the recommendations of the Nomenclature Committee of the International Union of Biochemistry and Molecular Biology. ${ }^{36}$

\section{Animals}

WT(C57BL/6J; Charles River Laboratories Japan, Inc., Yokohama, Kanagawa, Japan) and apoE-deficient male mice (B6.129P2Apoe $^{\mathrm{tm} 1 \mathrm{Unc}} / \mathrm{J}$; The Jackson Laboratory, United States), which were acquired at 6 or 8 weeks of age, were quarantined and acclimated for at least 7 days and were observed daily for clinical signs during and after the quarantine period. The ex vivo antiplatelet study was conducted in compliance with the Act on Welfare and Management of Animals of Japan and the Guidance for Animal Care and Use of Ina Research Inc., in accordance with the protocol (study no. IP15213) approved by the Institutional Animal Care and Use Committee of Ina Research Inc., which is fully accredited by AAALAC International (accredited unit no. 001107). The thrombosis study was conducted as approved by the Institutional Animal Experiment Committee of Nissei Bilis Co., Ltd. (permit no. 1505-08). These models of atherothrombosis in mice have been in use for several years. ${ }^{30-35}$ All studies involving mice were reported in accordance with the ARRIVE guidelines. ${ }^{37,38}$

\section{Drug Administration}

Clopidogrel was suspended in $5 \%$ gum arabic solution and administered orally to mice once daily for 5 days. The dose of clopidogrel was determined according to the results of pilot ex vivo platelet aggregation studies using platelet-rich plasma, which indicated that administration of $10 \mathrm{mg} / \mathrm{kg} / \mathrm{d}$ of clopidogrel for 5 days completely inhibited ADP-induced platelet aggregation in WT mice (data not shown).

\section{Induction of Diabetes Mellitus}

DM was induced in mice that did not exhibit detectable abnormalities during the quarantine period. Citrate buffer solution or STZ (55 mg/kg/d, intraperitoneally) was administered for 5 days to 9-week-old apoE-deficient and WT mice.

\section{$\mathrm{FeCl}_{3}$-Induced Thrombosis}

Thrombus formation was induced in 21-week-old mice (12 weeks after STZ administration). Mice were anesthetized using isoflurane, and the right carotid artery was exposed. A soft-cuff blood flow probe (MC0.5PSB, Transonic Systems Inc., New York, United States) was placed on the right carotid artery, and blood flow was continuously monitored using a pulsed Doppler flow meter (TS420, Transonic Systems Inc.). Subsequently, 2 hours after the last dose of clopidogrel, filter paper (qualitative filter paper no. 2; Advantec Toyo Kaisha, Ltd., Tokyo, Japan) trimmed to $1 \times 2 \mathrm{~mm}$ and saturated with a $10 \% \mathrm{FeCl}_{3}$ solution was placed on the arterial surface for 3 minutes. The filter paper was removed, and the time in seconds to first occlusion (TTO), defined as the time to arrest blood flow for $>1$ minute, was measured. Blood flow was monitored for 60 minutes after placement of the filter paper. If blood flow was not arrested for $>1$ minute during the 60-minute observation, TTO was defined as 60 minutes, and monitoring was terminated.

\section{Blood Biochemistry}

After completing the measurement of blood flow, a blood sample $(\sim 500 \mu \mathrm{L})$ was collected from the abdominal vein, transferred to a micro-blood collection tube, and serum was collected after centrifugation $(1,609 \times \mathrm{g}$, for 10 minutes at room temperature) using a Model 6000 centrifuge (KUBOTA Manufacturing Corporation, Osaka, Japan). All measurements were performed in duplicate. Insulin was measured using a Mouse Insulin ELISA Kit (TMB) (AKRIN-011T; Shibayagi Co., Ltd., Gunma, Japan) according to the manufacturer's instructions. 
Glucose, total cholesterol, triglycerides, and free fatty acids were measured using the Glucose C2-Test Wako (mutarotase-GOD method), the Cholesterol E-Test Wako (cholesterol oxidase DAOS method), the triglyceride E-Test Wako (glycerol3-phosphate oxidase DAOS method), and the NEFA C-Test Wako (acyl-CoA synthetase and acyl-CoA oxidase method; WAKO Pure Chemical Industries, Ltd., Osaka, Japan), respectively. All measurements were performed according to the instructions included in each kit.

\section{Pathological Evaluation}

After blood collection, mice were euthanized by exsanguination under isoflurane anesthesia with perfusion of saline from the left ventricle to incisions in the abdominal artery and vein. Perfusion fixation was performed using $10 \%$ neutral-buffered formalin for 5 to 10 minutes, and the $\mathrm{FeCl}_{3}$-injured regions of the right carotid arteries and the approximately identical regions of the left carotid arteries were collected and fixed in $10 \%$ neutral-buffered formalin. Specimens were isolated from three areas of the carotid arteries as follows: the approximate midsection of the $\mathrm{FeCl}_{3}$-injured region, 100 - $\mu \mathrm{m}$ distal from the midsection, and 200- $\mu \mathrm{m}$ distal from the midsection. Paraffin sections were prepared, and each region was stained using hematoxylin-eosin (HE) and an Elastica van Gieson (EVG). For EVG-stained specimens, the luminal area (A) and the thrombus area $(\mathrm{T})$ were measured using image analysis software (Win ROOF 2013; Mitani Corporation, Fukui, Japan), and lumen stenosis $(100 \times \mathrm{T} / \mathrm{A})$ was calculated. Mean values of $\mathrm{T}$ and lumen stenosis in three positions were calculated.

\section{Detection of Activated Glycoprotein IIb/IIla and P-Selectin on Platelets}

Citrated blood samples were collected from the posterior vena cava of mice 2 hours after the final dose of clopidogrel. Blood samples were added to tubes containing an FITC-labeled antiGPIX antibody, a PE-labeled anti-GPIIb/IIIa antibody or an antiP-selectin antibody, an agonist, and saline. ADP or PAR4 TRAP was used as agonists. Since preliminary studies showed little significant expression of P-selectin in response to ADP stimulation, we utilized PAR4 TRAP to induce platelet P-selectin expression in mice. The tubes were then gently stirred and allowed to stand for 15 minutes at room temperature. FACS lysing solution (Becton, Dickinson and Company, New Jersey, United States) was added, and blood cells were fixed for 30 minutes under refrigeration. A FACS Canto II (Nippon Becton, Dickinson and Company, Tokyo, Japan) was used for the analysis. FITC-positive cells were defined as platelets, and the intensities of PE fluorescence specific to 10,000 platelets were measured. The geometric mean calculated from the histograms of PE fluorescence intensities was defined as the mean fluorescence intensity (MFI).

\section{Data and Statistical Analysis}

The data and statistical analysis comply with the recommendations on experimental design and analysis in pharmacology. ${ }^{39}$ The data for biochemical parameters, platelet activation markers, TTO, thrombus area, and lumen stenosis are presented as the mean \pm or + standard error(SE).Student's $t$-test was conducted for each comparison. A two-way analysis of variance (ANOVA) was performed to evaluate the data for treatment (vehicle and clopidogrel) and genotype (WT mice and apoE-deficient mice) as well as treatment (vehicle and clopidogrel) and diabetes (nondiabetic apoE-deficient mice and diabetic apoE-deficient mice). A statistically significant difference was defined as $p<0.05$. Statistical analyses were performed using SAS 9.1 or 9.3 for Windows (SAS Institute Inc., North Carolina, United States) with EXSUS Version 8.0 (Arm Systex Co., Ltd., Osaka, Japan) or the INATOX-DP (SAS) system (Ina Research Inc., Nagano, Japan).

\section{Results}

\section{Blood Biochemistry}

The blood levels of insulin, glucose, total cholesterol, triglyceride, and free fatty acids in WT mice, apoE-deficient mice, and diabetic apoE-deficient mice are shown in -Table 1. The mean insulin levels were as follows: vehicle-treated group, $1.1 \pm 0.1 \mathrm{ng} / \mathrm{mL}$; WT mice, $0.4 \pm 0.1 \mathrm{ng} / \mathrm{mL}$; apoE-deficient mice and diabetic apoE-deficient mice, $0.0 \pm 0.0 \mathrm{ng} / \mathrm{mL}$. Insulin levels of diabetic apoE-deficient mice were lower compared with those of WT mice $(p<0.001)$ and nondiabetic apoE-deficient mice $(p<0.05)$. The mean glucose level of the vehicle-treated

Table 1 Effects of clopidogrel on blood physiological parameters in wild-type, apoE-deficient, and diabetic apoE-deficient mice

\begin{tabular}{|l|l|l|l|l|l|l|l|}
\hline Mice & Compound & $\boldsymbol{n}$ & $\begin{array}{l}\text { Insulin } \\
(\mathbf{n g} / \mathbf{m L})\end{array}$ & $\begin{array}{l}\text { Glucose } \\
(\mathbf{m g} / \mathbf{d L})\end{array}$ & $\begin{array}{l}\text { Total cholesterol } \\
(\mathbf{m g} / \mathbf{d L})\end{array}$ & $\begin{array}{l}\text { Triglyceride } \\
(\mathbf{m g} / \mathbf{d L})\end{array}$ & $\begin{array}{l}\text { Free fatty acid } \\
(\mathbf{m E q} / \mathrm{L})\end{array}$ \\
\hline \multirow{3}{*}{ WT } & Vehicle & 10 & $1.1 \pm 0.1$ & $329 \pm 32$ & $102.8 \pm 3.1$ & $77.2 \pm 11.4$ & $1.03 \pm 0.05$ \\
\cline { 2 - 8 } & Clopidogrel & 10 & $1.3 \pm 0.2$ & $297 \pm 15$ & $99.2 \pm 2.4$ & $73.3 \pm 9.0$ & $0.96 \pm 0.03$ \\
\hline \multirow{2}{*}{ ApoE-deficient } & Vehicle & 10 & $0.4 \pm 0.1^{\mathrm{a}}$ & $261 \pm 25$ & $667.6 \pm 37.8^{\mathrm{b}}$ & $144.1 \pm 5.8^{\mathrm{b}}$ & $1.58 \pm 0.12^{\mathrm{b}}$ \\
\cline { 2 - 8 } & Clopidogrel & 10 & $0.7 \pm 0.1^{\mathrm{a}}$ & $279 \pm 32$ & $698.6 \pm 28.0^{\mathrm{b}}$ & $143.9 \pm 9.9^{\mathrm{b}}$ & $1.49 \pm 0.05^{\mathrm{b}}$ \\
\hline \multirow{2}{*}{$\begin{array}{l}\text { Diabetic } \\
\text { apoE-deficient }\end{array}$} & Vehicle & 10 & $0.0 \pm 0.0^{\mathrm{b}}$ & $548 \pm 15^{\mathrm{b}}$ & $1,671.1 \pm 149.7^{\mathrm{b}}$ & $192.5 \pm 18.6^{\mathrm{b}}$ & $3.54 \pm 0.54^{\mathrm{b}}$ \\
\cline { 2 - 8 } & Clopidogrel & 10 & $0.0 \pm 0.0^{\mathrm{b}}$ & $557 \pm 20^{\mathrm{b}}$ & $1,714.4 \pm 156.2^{\mathrm{b}}$ & $190.6 \pm 20.2^{\mathrm{b}}$ & $3.39 \pm 0.56^{\mathrm{b}}$ \\
\hline
\end{tabular}

Abbreviations: apoE, apolipoprotein E; WT, wild-type.

Notes: Clopidogrel $(10 \mathrm{mg} / \mathrm{kg} / \mathrm{d})$ was orally administered once a day for 5 days. There were no statistical differences between each vehicle and clopidogrel groups in WT, apoE-deficient, and STZ-induced diabetic apoE-deficient mice.

${ }_{\mathrm{a}}^{\mathrm{a}}<0.01$.

${ }^{\mathrm{b}} p<0.001$ versus each WT group. 
diabetic apoE-deficient mice was $548 \pm 15 \mathrm{mg} / \mathrm{dL}$, which was significantly higher compared with those of the vehicle-treated WT mice $(329 \pm 32 \mathrm{mg} / \mathrm{dL}, p<0.001)$ and the vehicle-treated nondiabetic apoE-deficient mice $(261 \pm 25 \mathrm{mg} / \mathrm{dL}, p<0.001)$. The total cholesterol, triglyceride, and free fatty acid levels in the vehicle-treated diabetic apoE-deficient mice were $1671.1 \pm 149.7 \mathrm{mg} / \mathrm{dL}, 192.5 \pm 18.6 \mathrm{mg} / \mathrm{dL}$, and $3.54 \pm 0.54$ $\mathrm{mEq} / \mathrm{L}$, respectively, which were significantly higher compared with those of the vehicle-treated WT mice $(p<0.001)$. There were no statistically significant differences between any vehicle and clopidogrel group among the WT, apoE-deficient, and diabetic apoE-deficient mice.

\section{Effect of Clopidogrel on Thrombus Formation: Blood Flow Analyses}

The patency of the carotid artery following $\mathrm{FeCl}_{3}$-induced injury in each animal is shown in - Fig. 1. In the three vehicle groups, blood flow stopped in most mice soon after the application of $\mathrm{FeCl}_{3}$, and arterial occlusion persisted thereafter. In contrast, in clopidogrel-treated WT and apoE-deficient mice, blood flow did not stop in all mice. In diabetic apoE-deficient mice, blood flow was disrupted in 6 of 10 mice. Typical tracings of carotid artery blood flow after the arterial injury show that blood flow stopped in diabetic apoE-deficient mice despite clopidogrel pretreatment (-supplementary Fig. S1, available online).

We further evaluated TTO as a marker of thrombus formation. The mean TTO values were as follows: vehicle group, $594 \pm 37$ seconds in WT mice; $530 \pm 21$ seconds in apoE-deficient mice; and $487 \pm 13$ seconds in the diabetic

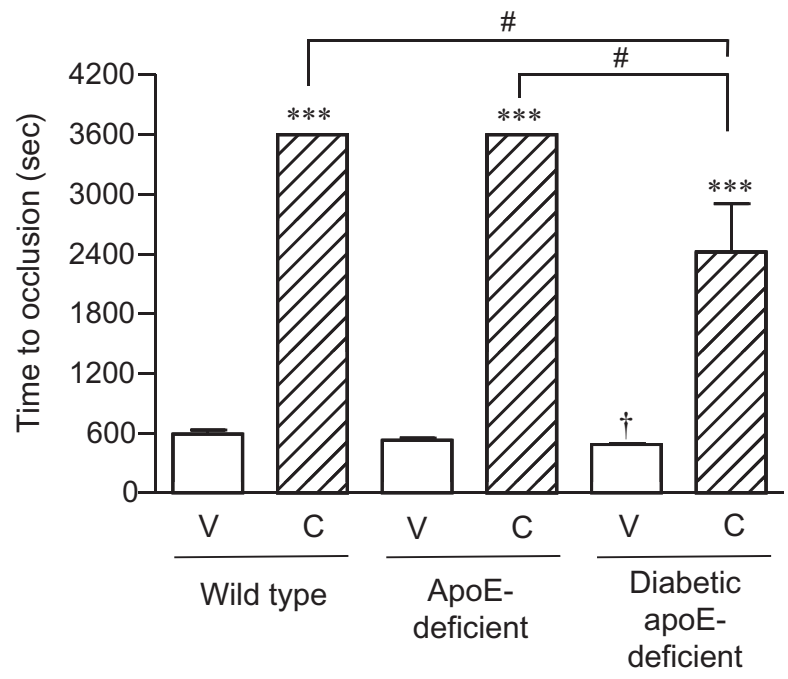

Fig. 2 Effect of clopidogrel on time to first occlusion. Clopidogrel (C) at $10 \mathrm{mg} / \mathrm{kg} / \mathrm{d}$ (orally) or vehicle (V) was administered once daily for 5 days to wild-type (WT), apoE-deficient, and diabetic apoE-deficient mice ( $n=10$ per group). Carotid artery occlusion was initiated by application of $\mathrm{FeCl}_{3} 2$ hours after the last dose of clopidogrel, arterial blood flow was monitored, and the time in seconds to first occlusion was determined. The results are presented as the mean $+\mathrm{SE}$ $(n=10) .{ }^{* * *} p<0.001$ versus each vehicle group, ${ }^{\dagger} p<0.05$ versus the vehicle group of WT mice, ${ }^{\#} p<0.05$ (Student's $t$-test).

apoE-deficient mice (-Fig. 2). The mean TTO of diabetic apoE-deficient mice was significantly shorter compared with that of the WT mice $(p<0.05)$. In the clopidogrel-treated groups, the mean TTO values were $3,600 \pm 0$ seconds

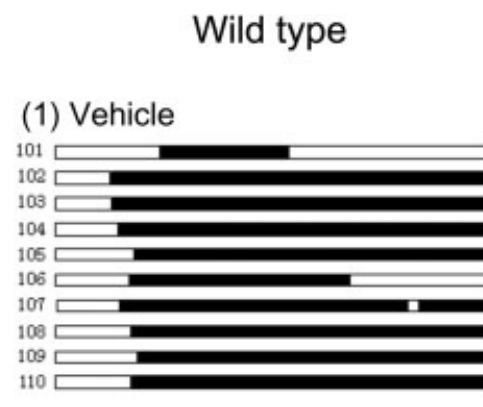

\section{(2) Clopidogrel}

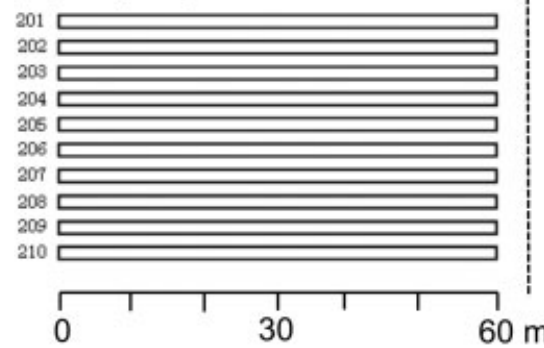

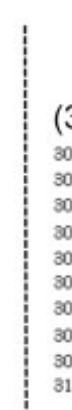

ApoE-deficient

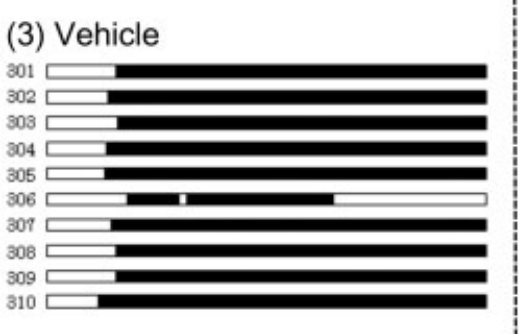

\section{(4) Clopidogrel}

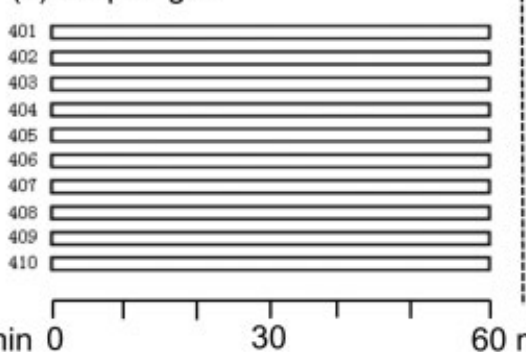

$60 \min 0$

\section{Diabetic apoE-deficient}

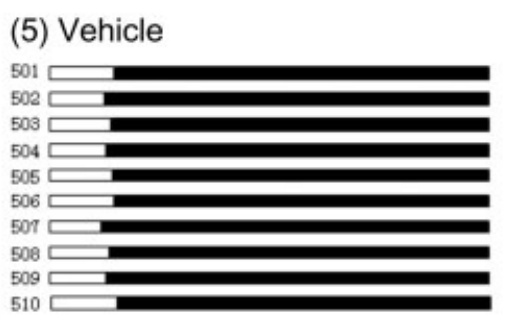

\section{(6) Clopidogrel}

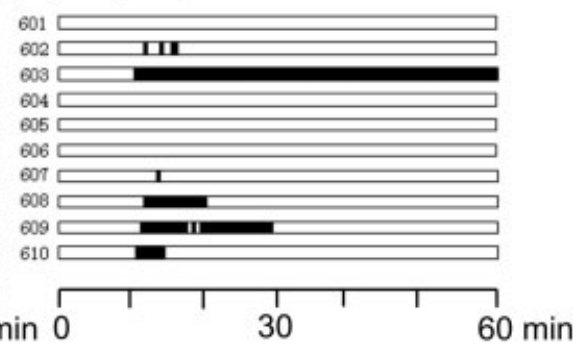

Patent artery

Occluded artery

Fig. 1 Effects of clopidogrel on the patency of carotid arteries. Clopidogrel (10 mg/kg/d, orally) or vehicle was administered once daily for 5 days. Carotid artery occlusion was initiated by application of $\mathrm{FeCl}_{3}$ and blood flow was determined for 1 hour. Individual patency data are shown for vehicle-treated WT (1), clopidogrel-treated WT (2), vehicle-treated apoE-deficient (3), clopidogrel-treated apoE-deficient (4), vehicle-treated diabetic apoE-deficient (5), and clopidogrel-treated diabetic apoE-deficient groups (6). Open and filled bars indicate patent and occluded arteries, respectively. The number on the left side of each column represents animal ID number. apoE, apolipoprotein E; WT, wild-type. 
$(p<0.001)$ in WT mice, $3,600 \pm 0$ seconds $(p<0.001)$ in apoE-deficient mice, and $2,421 \pm 481$ seconds $(p<0.001)$ in diabetic apoE-deficient mice (-Fig. 2). The mean TTO values of the clopidogrel-treated groups were significantly prolonged in WT mice, apoE-deficient mice, and diabetic apoE-deficient mice compared with those of each vehicle group; however, the mean TTO of clopidogrel-treated diabetic apoE-deficient mice was significantly shorter compared with those of clopidogrel-treated WT and apoE-deficient mice (each $p<0.05$ ).

\section{Effect of Clopidogrel on Thrombus Formation: Pathological Evaluation}

HE-stained cross-sections of injured carotid arteries show the presence of large thrombi in all vehicle-treated mice and clopidogrel-treated diabetic apoE-deficient mice (-Fig. 3). There were no significant differences among the mean thrombus areas of the vehicle groups: $147,174 \pm 9,936 \mu \mathrm{m}^{2}$ in WT mice, $149,814 \pm 8,606 \mu^{2}$ in apoE-deficient mice, and $121,557 \pm 14,916 \mu \mathrm{m}^{2}$ in diabetic apoE-deficient mice (-Fig. 4). The mean thrombus areas of the clopidogrel groups were significantly reduced in WT mice $\left(21,272 \pm 7,787 \mu \mathrm{m}^{2}\right.$, $p<0.001)$ and in apoE-deficient mice $\left(37,501 \pm 7,034 \mu \mathrm{m}^{2}\right.$, $p<0.0001$ ) compared with each vehicle group. The mean thrombus area of the clopidogrel-treated diabetic apoE-deficient mice was $119,280 \pm 16,835 \mu^{2}$, and a statistically significant effect of clopidogrel was not observed compared with the corresponding vehicle treatment. The mean thrombus area in diabetic apoE-deficient mice was significantly larger compared with those of WT mice $(p<0.001)$ and nondiabetic apoE-deficient mice $(p<0.001)$.

Mean lumen stenosis was not significantly different among the vehicle groups as follows: $95.0 \pm 2.2 \%$ in WT mice, $96.2 \pm 1.1 \%$ in apoE-deficient mice, and $87.7 \pm 6.5 \%$ in diabetic apoE-deficient mice (-Fig. 4). Clopidogrel significantly reduced mean lumen stenosis in WT mice $(18.1 \pm 6.0 \%, \quad p<0.001)$ and in apoE-deficient mice (34.5 $\pm 6.4 \%, p<0.001)$ compared with each vehicle group. Mean lumen stenosis in clopidogrel-treated diabetic apoEdeficient mice was $78.4 \pm 7.0 \%$, which was not significantly different from that of the corresponding vehicle-treated mice. Mean lumen stenosis in diabetic apoE-deficient mice was significantly higher compared with those of WT mice $(p<0.001)$ and apoE-deficient mice $(p<0.001)$.
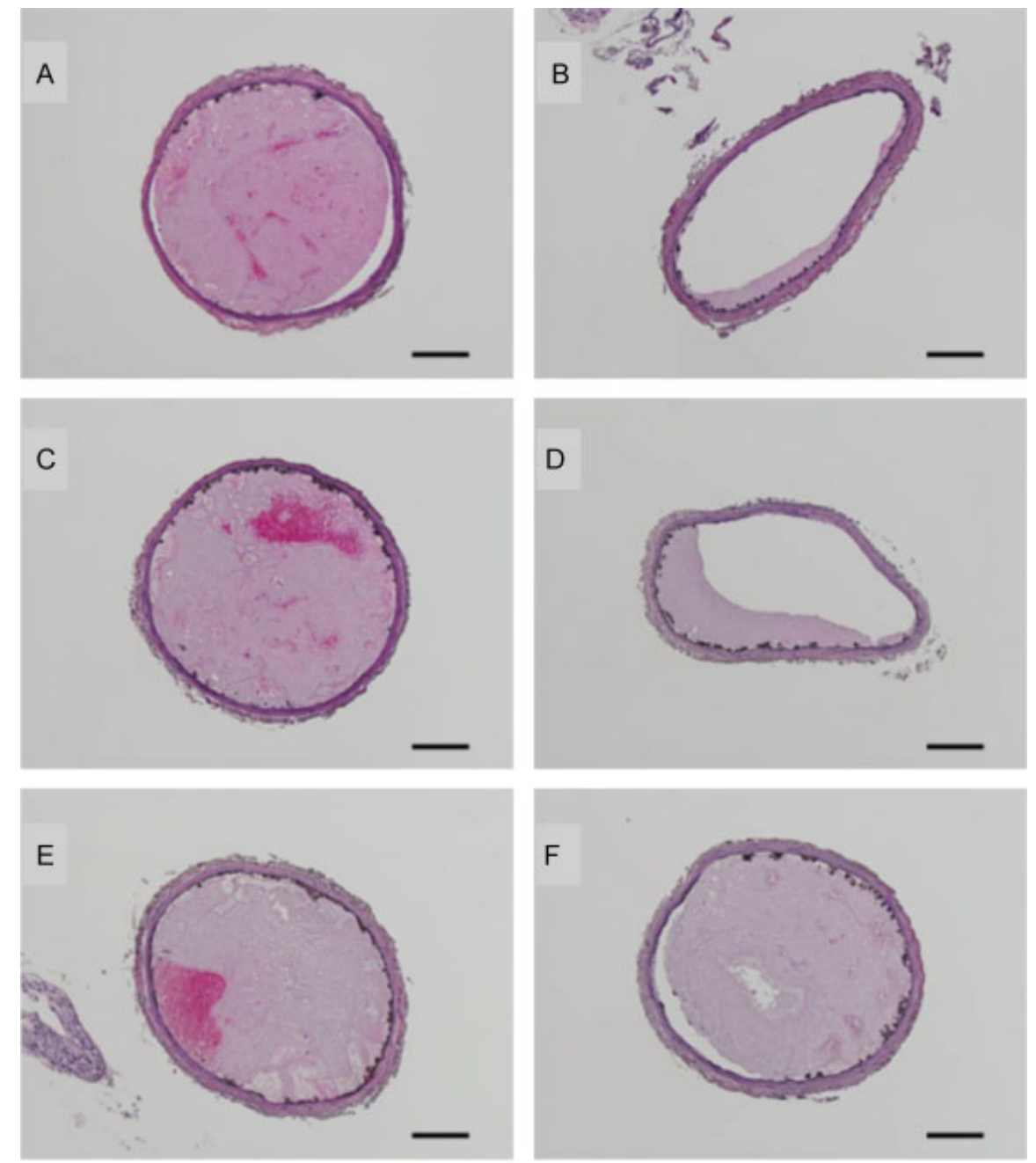

Fig. 3 Hematoxylin-eosin-stained cross-sections of injured carotid arteries. (A) Vehicle-treated wild-type (WT) (animal ID no. 105 in - Fig. 1); (B) clopidogrel-treated WT (no. 202); (C) vehicle-treated apoE-deficient (no. 308); (D) clopidogrel-treated apoE-deficient (no. 406);

(E) vehicle-treated diabetic apoE-deficient (no. 501); and (F) clopidogrel-treated diabetic apoE-deficient mice (no. 607). Scale bar $=100 \mu \mathrm{m}$. 
(A)Thrombus area

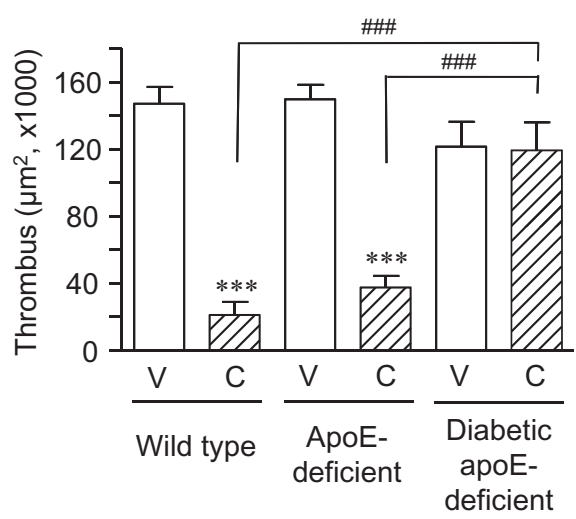

(B) Lumen stenosis

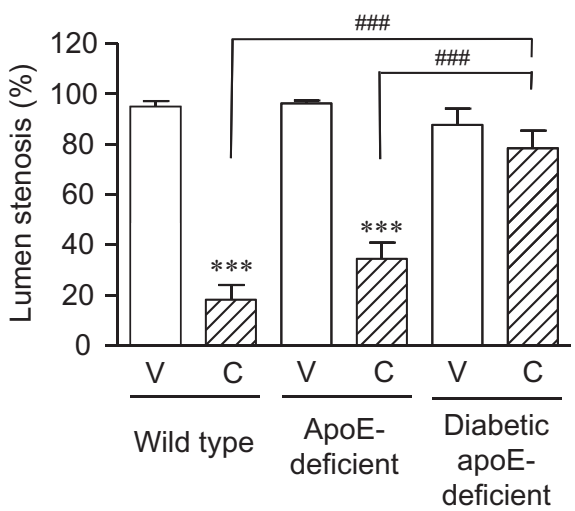

Fig. 4 Effects of clopidogrel on morphometric parameters of injured carotid arteries, thrombus area (A) and lumen stenosis (B). Clopidogrel (C) at $10 \mathrm{mg} / \mathrm{kg} / \mathrm{d}$ (orally) or vehicle (V) was administered once daily for 5 days to wild-type (WT), apoE-deficient, and diabetic apoE-deficient mice ( $n=10$ per group) and arterial occlusion was induced 2 hours after the last dose of clopidogrel. After completing blood flow monitoring, mice were euthanized. The $\mathrm{FeCl}_{3}$-injured regions of the carotid arteries were collected, further fixed in $10 \%$ neutral-buffered formalin and paraffin sections prepared, and stained. The lumen and thrombotic areas were measured using an image analysis software (WinROOF 2013), and lumen stenosis $\left(100 \times\right.$ thrombus area/lumen area) was calculated. Results are presented as the mean $+\operatorname{SE}(n=10) .{ }^{* * *} p<0.001$ versus each

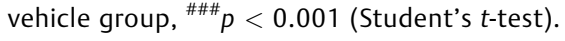

\section{Two-Way Analysis of Variance}

Two-way ANOVA revealed associations between DM and clopidogrel according to TTO $(p<0.05)$, thrombus $(p<0.001)$, and lumen stenosis $(p<0.001)$, but not with all biochemical parameters. These results confirm that the antithrombotic effects of clopidogrel were attenuated in diabetic apoE-deficient mice. There was no significant association between genotype of mice and clopidogrel for all parameters, indicating that apoE deficiency did not influence the effects of clopidogrel.

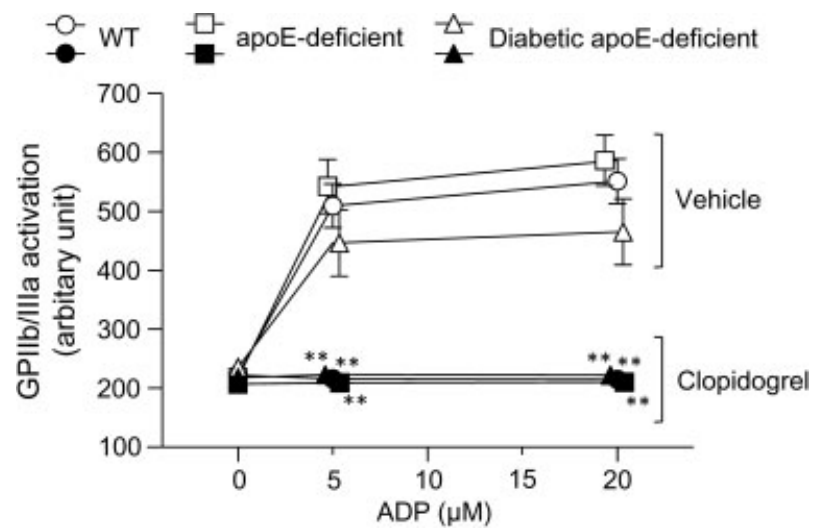

Fig. 5 Effects of clopidogrel on platelet expression of ADP-induced activated GPIIb/IIla expression. Clopidogrel $(10 \mathrm{mg} / \mathrm{kg} / \mathrm{d})$ or vehicle was administered orally once daily for 5 days to wild-type (WT), apoE-deficient, and streptozotocin-induced diabetic apoE-deficient mice, and blood collected 2 hours after the last dose. Ex vivo expression of activated GPIIb/IIla on platelets induced by 5 and $20 \mu \mathrm{M}$ ADP was assessed using a flow cytometer. In the vehicle groups, ADP stimulation resulted in a significant increase in the expression of activated platelet GPIIb/IIla compared with no agonist ( $p<0.01$ for diabetic apoE-deficient mice, $p<0.001$ for other groups). The results are presented as mean \pm SE $(n=10) .{ }^{* *} p<0.01$ versus corresponding vehicle group (Student's $t$-test).

\section{Platelet Surface Expression of ADP-Induced Activated GPIIb/IIIa}

In the vehicle groups, treatment with ADP ( 5 and $20 \mu \mathrm{M}$ ) significantly increased the expression of activated GPIIb/IIIa on platelets compared with no agonist (-Fig. 5) in WT, apoEdeficient, and diabetic apoE-deficient mice $(p<0.01)$. There was no significant difference in levels of activated GPIIb/IIIa among the vehicle-treated WT, apoE-deficient, and diabetic apoE-deficient mice. Clopidogrel treatment resulted in nearcomplete inhibition of ADP-induced activated GPIIb/IIIa expression compared with each vehicle group ( $p<0.01$ each).

\section{Effect of Clopidogrel on PAR4-Activating Peptide- Induced Expression of Platelet P-Selectin}

In the vehicle groups, treatment with PAR4 TRAP (100 and $300 \mu \mathrm{M})$ significantly increased the expression of platelet P-selectin compared with those of the controls $(p<0.001$, all groups; - Fig. 6). Of note, the level of P-selectin expression in diabetic apoE-deficient mice induced by $100 \mu \mathrm{M}$ PAR4 TRAP was significantly increased compared with those in WT mice and non-diabetic apoE-deficient mice ( $p<0.05$ each). Clopidogrel treatment significantly inhibited PAR4 TRAP-induced platelet P-selectin expression compared with that of each vehicle group $(p<0.05$, diabetic apoE-deficient mice, 300 $\mu M$ PAR4 TRAP; $p<0.001$ for the other groups). However, the degree of the inhibition differed among the groups as follows: the expression of P-selectin induced by PAR4 TRAP in the diabetic apoE-deficient mice was significantly higher compared with that of WT or nondiabetic apoE-deficient mice ( $p<0.001$, all groups).

\section{Discussion}

In this study, blood biochemistry values revealed unmeasurable insulin levels and a significant increase in glucose in diabetic apoE-deficient mice compared with those of WT and 


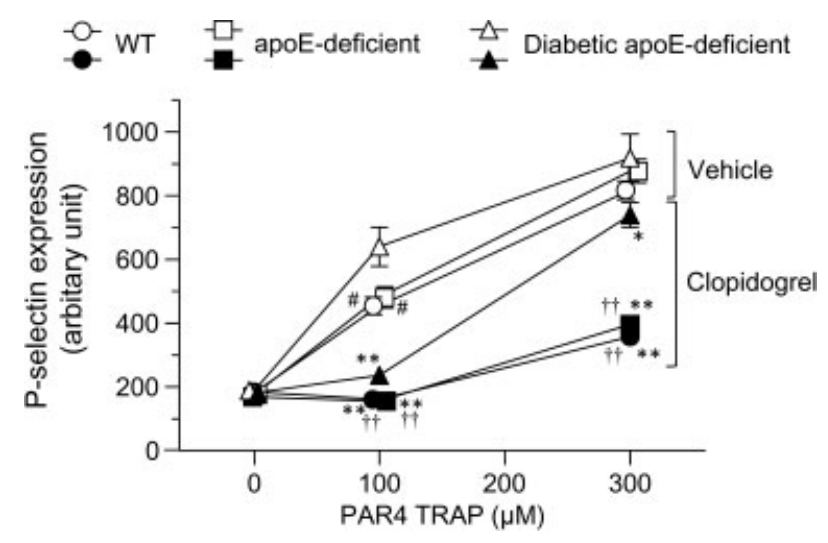

Fig. 6 Effects of clopidogrel on PAR4 TRAP-induced expression of platelet P-selectin. Clopidogrel $(10 \mathrm{mg} / \mathrm{kg} / \mathrm{d})$ or vehicle was administered orally once daily for 5 days to wild-type (WT), apoE-deficient, and diabetic apoE-deficient mice, and blood collected 2 hours after the last dose. Ex vivo expression of P-selectin on platelets induced by 100 and $300 \mu \mathrm{M}$ PAR4 TRAP was assessed using a flow cytometer. In the vehicle groups, PAR4 TRAP stimulation resulted in a significant increase in platelet P-selectin expression compared with no agonist ( $p<0.001$, all groups). The results are presented as the mean \pm SE $(n=10)$. ${ }^{*} p<0.05,{ }^{* *} p<0.01$ versus corresponding vehicle group; ${ }^{\#} p<0.05$ versus the vehicle group of diabetic apoE-deficient mice; ${ }^{\dagger \dagger} p<0.01$ versus clopidogrel group of diabetic apoE-deficient mice (Student's t-test).

nondiabetic apoE-deficient mice, thus indicating induction of DM. Repeated oral doses of clopidogrel markedly inhibited acute thrombus formation following $\mathrm{FeCl}_{3}$-induced injury of carotid arteries in WT and apoE-deficient mice, consistent with previous reports. ${ }^{40,41}$ In contrast, the antithrombotic effect of clopidogrel, determined by measurements of blood flow, significantly decreased in diabetic apoE-deficient mice compared with those of WT and nondiabetic apoE-deficient mice. To the best of our knowledge, the present study is the first to report a mouse model for studying the diabetesassociated reduction of the response to clopidogrel and therefore represents a unique and potentially valuable approach to identify mechanisms underlying DM-associated impairment of antiplatelet and antithrombotic responses to clopidogrel.

Pathological evaluation, which measured thrombus area and stenosis, further confirmed a significant reduction of the antithrombotic effect of clopidogrel; indeed the extent of the loss of protection against thrombus formation and stenosis was greater than that of blood flow measurements using TTO. The TTO is a commonly used index for the dynamic assessment of thrombus formation in several models of thrombosis. ${ }^{34,42}$ However, our results showed that at least in this model, direct pathological evaluation may be more sensitive for detecting impaired antithrombotic responses.

Impaired inhibition of $\mathrm{P}^{2} \mathrm{Y}_{12}$ by clopidogrel in DM is largely attributable to attenuation of the PK profile of clopidogrel. ${ }^{29}$ Thus, when we determined the antiplatelet effects of clopidogrel using the present model, we found that ADP-induced platelet activation was similarly inhibited in each group of mice, suggesting that in this model, production of clopidogrel
AM was similar among the mice of each genotype/phenotype. Therefore, a mechanism other than those that alter the PK profile may contribute to the impaired response by clopidogrel in STZ-treated diabetic apoE-deficient mice.

Platelet activation is enhanced both in patients with $\mathrm{DM}^{43}$ and in animal models of diabetes. ${ }^{44}$ Although the cause of increased platelet activation is multifactorial, ${ }^{45}$ enhancement of ADP-induced platelet activation ${ }^{46,47}$ may contribute to the higher rates of ischemic complications in patients with DM. ${ }^{45}$ In this study, levels of ADP-induced platelet GPIIb/IIIa activation among the three genotypes of mice treated with vehicle were not significantly different. Therefore, diabetesassociated enhancement of ADP-induced platelet activation likely does not underlie the impaired antithrombotic effect in diabetic apoE-deficient mice.

In contrast, upon examination of the effects of clopidogrel on PAR4 TRAP-induced activation of platelets, we found an interesting reduction in the antiplatelet effect in diabetic apoE-deficient mice compared with those in WT and nondiabetic apoE-deficient mice. These data suggest that any changes in the effect of clopidogrel on thrombin-induced platelet activation may, in part, mediate the impaired antithrombotic effect of clopidogrel in diabetic apoE-deficient mice. In this study, significant enhancement of PAR4 TRAPinduced platelet activation was observed in diabetic platelets stimulated with PAR4 TRAP $(100 \mu \mathrm{M})$, which is consistent with previous clinical findings that significant enhancement of PAR4 TRAP-induced platelet aggregation occurs in patients with DM. ${ }^{48}$ Moreover, the effects of thienopyridines on thrombin-induced platelet activation are dependent on thrombin concentrations because increased activation of the thrombin receptor of platelets may reduce the antiplatelet effects of thienopyridines. ${ }^{49-51}$ These findings suggest that greater DM-associated enhancement of platelet activation via thrombin receptors in diabetic mice may reduce the antithrombotic effects of clopidogrel. Prasugrel ${ }^{3,4}$ and ticagrelor, ${ }^{6,7}$ which exert more potent pharmacodynamic inhibition than previous $\mathrm{P}_{2} \mathrm{Y}_{12}$ antagonists, are associated with increased reduction of cardiovascular risk in patients with DM compared with clopidogrel. ${ }^{52,53}$ These findings may be partially explained by the more potent inhibition of thrombin-induced platelet activation by prasugrel and ticagrelor.

These data suggest that apoE-deficient mice with STZ-treated diabetes will serve as a useful model to conduct further studies of the impaired responses to clopidogrel found in patients with DM, which may partially reflect a reduction of the effect of clopidogrel on thrombin-induced platelet activation.

\section{Conflict of Interest}

Joseph A. Jakubowski (retired) is a minor shareholder of Eli Lilly and Company. Other authors are employees of Daiichi Sankyo Co., Ltd.

\section{Acknowledgments}

We thank Nissei Bilis Co., Ltd. and Ina Research Inc. for their expert technical contributions. 


\section{References}

1 Levine GN, Bates ER, Blankenship JC, et al; American College of Cardiology Foundation; American Heart Association Task Force on Practice Guidelines; Society for Cardiovascular Angiography and Interventions. 2011 ACCF/AHA/SCAI Guideline for Percutaneous Coronary Intervention. A report of the American College of Cardiology Foundation/American Heart Association Task Force on Practice Guidelines and the Society for Cardiovascular Angiography and Interventions. J Am Coll Cardiol 2011;58(24):e44-e122

2 Anderson JL, Adams CD, Antman EM, et al. 2012 ACCF/AHA focused update incorporated into the ACCF/AHA 2007 guidelines for the management of patients with unstable angina/non-STelevation myocardial infarction: a report of the American College of Cardiology Foundation/American Heart Association Task Force on Practice Guidelines. J Am Coll Cardiol 2013;61(23):e179-e347

3 Sugidachi A, Ohno K, Ogawa T, Jakubowski J, Hashimoto M, Tomizawa A. A comparison of the pharmacological profiles of prasugrel and ticagrelor assessed by platelet aggregation, thrombus formation and haemostasis in rats. Br J Pharmacol 2013;169 (01):82-89

4 Wiviott SD, Braunwald E, McCabe CH, et al; TRITON-TIMI 38 Investigators. Prasugrel versus clopidogrel in patients with acute coronary syndromes. N Engl J Med 2007;357(20):2001-2015

5 Li YG, Ni L, Brandt JT, et al. Inhibition of platelet aggregation with prasugrel and clopidogrel: an integrated analysis in 846 subjects. Platelets 2009;20(05):316-327

6 VAN Giezen JJ, Nilsson L, Berntsson P, et al. Ticagrelor binds to human $\mathrm{P}_{2} \mathrm{Y}_{12}$ independently from ADP but antagonizes ADPinduced receptor signaling and platelet aggregation. J Thromb Haemost 2009;7(09):1556-1565

7 Wijeyeratne YD, Joshi R, Heptinstall S. Ticagrelor: a P2Y 12 antagonist for use in acute coronary syndromes. Expert Rev Clin Pharmacol 2012;5(03):257-269

8 Ferreiro JL, Angiolillo DJ. New directions in antiplatelet therapy. Circ Cardiovasc Interv 2012;5(03):433-445

9 Aradi D, Komócsi A, Price MJ, et al; Tailored Antiplatelet Treatment Study Collaboration. Efficacy and safety of intensified antiplatelet therapy on the basis of platelet reactivity testing in patients after percutaneous coronary intervention: systematic review and meta-analysis. Int J Cardiol 2013;167(05):2140-2148

10 Angiolillo DJ, Fernandez-Ortiz A, Bernardo E, et al. Variability in individual responsiveness to clopidogrel: clinical implications, management, and future perspectives. J Am Coll Cardiol 2007; 49(14):1505-1516

11 Bonello L, Tantry US, Marcucci R, et al; Working Group on High On-Treatment Platelet Reactivity. Consensus and future directions on the definition of high on-treatment platelet reactivity to adenosine diphosphate. J Am Coll Cardiol 2010;56(12):919-933

12 Price MJ, Coleman JL, Steinhubl SR, Wong GB, Cannon CP, Teirstein PS. Onset and offset of platelet inhibition after high-dose clopidogrel loading and standard daily therapy measured by a point-of-care assay in healthy volunteers. Am J Cardiol 2006;98(05):681-684

13 Price MJ. Diabetes mellitus and clopidogrel response variability. J Am Coll Cardiol 2014;64(10):1015-1018

14 Price MJ, Angiolillo DJ, Teirstein PS, et al. Platelet reactivity and cardiovascular outcomes after percutaneous coronary intervention: a time-dependent analysis of the Gauging Responsiveness with a VerifyNow P2Y12 assay: Impact on Thrombosis and Safety (GRAVITAS) trial. Circulation 2011;124(10):1132-1137

15 Stone GW, Witzenbichler B, Weisz G, et al; ADAPT-DES Investigators. Platelet reactivity and clinical outcomes after coronary artery implantation of drug-eluting stents (ADAPT-DES): a prospective multicentre registry study. Lancet 2013;382(9892):614-623

16 Brar SS, ten Berg J, Marcucci R, et al. Impact of platelet reactivity on clinical outcomes after percutaneous coronary intervention. A collaborative meta-analysis of individual participant data. J Am Coll Cardiol 2011;58(19):1945-1954
17 Price MJ, Baker BA, Jakubowski JA, Li W, Heiselman DE, Angiolillo DJ. Detecting a thienopyridine effect by platelet reactivity assessment and its implications for risk stratification. J Thromb Haemost 2014;12(04):560-563

18 Gurbel PA, Bliden KP, Hiatt BL, O'Connor CM. Clopidogrel for coronary stenting: response variability, drug resistance, and the effect of pretreatment platelet reactivity. Circulation 2003;107 (23):2908-2913

19 Campo G, Parrinello G, Ferraresi P, et al. Prospective evaluation of on-clopidogrel platelet reactivity over time in patients treated with percutaneous coronary intervention relationship with gene polymorphisms and clinical outcome. J Am Coll Cardiol 2011; 57(25):2474-2483

20 Price MJ, Murray SS, Angiolillo DJ, et al; GIFT Investigators. Influence of genetic polymorphisms on the effect of high- and standard-dose clopidogrel after percutaneous coronary intervention: the GIFT (Genotype Information and Functional Testing) study. J Am Coll Cardiol 2012;59(22):1928-1937

21 Hochholzer W, Trenk D, Fromm MF, et al. Impact of cytochrome P450 2C19 loss-of-function polymorphism and of major demographic characteristics on residual platelet function after loading and maintenance treatment with clopidogrel in patients undergoing elective coronary stent placement. J Am Coll Cardiol 2010; 55(22):2427-2434

22 Shuldiner AR, O'Connell JR, Bliden KP, et al. Association of cytochrome P450 2C19 genotype with the antiplatelet effect and clinical efficacy of clopidogrel therapy. JAMA 2009;302(08): 849-857

23 Ferreira IA, Mocking AI, Feijge MA, et al. Platelet inhibition by insulin is absent in type 2 diabetes mellitus. Arterioscler Thromb Vasc Biol 2006;26(02):417-422

24 Kannel WB, McGee DL. Diabetes and glucose tolerance as risk factors for cardiovascular disease: the Framingham study. Diabetes Care 1979;2(02):120-126

25 Stamler J, Vaccaro O, Neaton JD, Wentworth D. Diabetes, other risk factors, and 12-yr cardiovascular mortality for men screened in the Multiple Risk Factor Intervention Trial. Diabetes Care 1993;16 (02):434-444

26 Angiolillo DJ, Fernandez-Ortiz A, Bernardo E, et al. Platelet function profiles in patients with type 2 diabetes and coronary artery disease on combined aspirin and clopidogrel treatment. Diabetes 2005;54(08):2430-2435

27 Angiolillo DJ. Antiplatelet therapy in diabetes: efficacy and limitations of current treatment strategies and future directions. Diabetes Care 2009;32(04):531-540

28 Ang L, Palakodeti V, Khalid A, et al. Elevated plasma fibrinogen and diabetes mellitus are associated with lower inhibition of platelet reactivity with clopidogrel.J Am Coll Cardiol 2008;52(13):1052-1059

29 Angiolillo DJ, Jakubowski JA, Ferreiro JL, et al. Impaired responsiveness to the platelet $\mathrm{P}_{2} \mathrm{Y}_{12}$ receptor antagonist clopidogrel in patients with type 2 diabetes and coronary artery disease. J Am Coll Cardiol 2014;64(10):1005-1014

30 Fledderus JO, van Oostrom O, de Kleijn DP, et al. Increased amount of bone marrow-derived smooth muscle-like cells and accelerated atherosclerosis in diabetic apoE-deficient mice. Atherosclerosis 2013;226(02):341-347

31 Zhang Y, Wang X, Wang Y, Liu Y, Xia M. Supplementation of cyanidin-3-O- $\beta$-glucoside promotes endothelial repair and prevents enhanced atherogenesis in diabetic apolipoprotein E-deficient mice. J Nutr 2013;143(08):1248-1253

32 Lu Z, Zhang X, Li Y, Jin J, Huang Y. TLR4 antagonist reduces earlystage atherosclerosis in diabetic apolipoprotein E-deficient mice. J Endocrinol 2013;216(01):61-71

33 Lazaro I, Oguiza A, Recio C, et al. Targeting HSP90 ameliorates nephropathy and atherosclerosis through suppression of NF-KB and STAT signaling pathways in diabetic mice. Diabetes 2015; 64(10):3600-3613 
34 Ohno K, Tomizawa A, Jakubowski JA, Mizuno M, Sugidachi A. Prevention of occlusive arterial thrombus formation by a single loading dose of prasugrel suppresses neointimal hyperplasia in mice. Thromb Res 2015;136(06):1245-1251

35 Ohno K, Tomizawa A, Mizuno M, Jakubowski JA, Sugidachi A. Prasugrel, a platelet $\mathrm{P}_{2} \mathrm{Y}_{12}$ receptor antagonist, improves abnormal gait in a novel murine model of thrombotic hindlimb ischemia. J Am Heart Assoc 2016;5(04):e002889

36 Alexander SP, Mathie A, Peters JA. Guide to receptors and channels (GRAC), 5th edition. Br J Pharmacol 2011;164(Suppl 1):S1-S324

37 Kilkenny C, Browne W, Cuthill IC, Emerson M, Altman DG; NC3Rs Reporting Guidelines Working Group. Animal research: reporting in vivo experiments: the ARRIVE guidelines. Br J Pharmacol 2010; 160(07):1577-1579

38 McGrath JC, Drummond GB, McLachlan EM, Kilkenny C, Wainwright CL. Guidelines for reporting experiments involving animals: the ARRIVE guidelines. Br J Pharmacol 2010;160(07): 1573-1576

39 Curtis MJ, Bond RA, Spina D, et al. Experimental design and analysis and their reporting: new guidance for publication in BJP. Br J Pharmacol 2015;172(14):3461-3471

40 Kawasaki T, Taniguchi M, Moritani Y, et al. Pharmacological properties of YM-254890, a specific $\mathrm{G} \alpha_{\mathrm{q} / 11}$ inhibitor, on thrombosis and neointima formation in mice. Thromb Haemost 2005; 94(01):184-192

41 Hu L, Fan Z, Du H, et al. BF061, a novel antiplatelet and antithrombotic agent targeting $\mathrm{P}_{2} \mathrm{Y}_{12}$ receptor and phosphodiesterase. Thromb Haemost 2011;106(06):1203-1214

42 Tomizawa A, Ohno K, Jakubowski JA, Mizuno M, Sugidachi A. Prasugrel reduces ischaemic infarct volume and ameliorates neurological deficits in a non-human primate model of middle cerebral artery thrombosis. Thromb Res 2015;136(06):1224-1230

43 Bhatt DL. What makes platelets angry: diabetes, fibrinogen, obesity, and impaired response to antiplatelet therapy? J Am Coll Cardiol 2008;52(13):1060-1061

44 Rozalski M, Kassassir H, Siewiera K, Klepacka A, Sychowski R, Watala C. Platelet activation patterns are different in mouse models of diabetes and chronic inhibition of nitric oxide synthesis. Thromb Res 2014;133(06):1097-1104

45 Kumbhani DJ, Marso SP, Alvarez CA, McGuire DK. State-of-the-art: hypo-responsiveness to oral antiplatelet therapy in patients with type 2 diabetes mellitus. Curr Cardiovasc Risk Rep 2015;9:4

46 Sagel J, Colwell JA, Crook L, Laimins M. Increased platelet aggregation in early diabetes mellitus. Ann Intern Med 1975;82(06): 733-738

47 Honour AJ, Hockaday TD. Increased sensitivity of in vivo platelet aggregation in rabbits after alloxan or streptozotocin. Br J Exp Pathol 1976;57(01):1-10

48 Schuette C, Steffens D, Witkowski M, et al. The effect of clopidogrel on platelet activity in patients with and without type-2 diabetes mellitus: a comparative study. Cardiovasc Diabetol 2015;14:15

49 Sugidachi A, Asai F, Ogawa $T$, Inoue $T$, Koike $H$. The in vivo pharmacological profile of CS-747, a novel antiplatelet agent with platelet ADP receptor antagonist properties. $\mathrm{Br} \mathrm{J}$ Pharmacol 2000;129(07):1439-1446

50 Gachet C, Stierlé A, Cazenave JP, et al. The thienopyridine PCR 4099 selectively inhibits ADP-induced platelet aggregation and fibrinogen binding without modifying the membrane glycoprotein IIb-IIla complex in rat and in man. Biochem Pharmacol 1990; 40(02):229-238

51 Jakubowski JA, Zhou C, Egan B, et al. Modification of the VerifyNow ${ }^{\circledR}$ P2Y12 test BASE channel to accommodate high levels of P2Y 12 antagonism. Platelets 2011;22(08):619-625

52 Wiviott SD, Braunwald E, Angiolillo DJ, et al; TRITON-TIMI 38 Investigators. Greater clinical benefit of more intensive oral antiplatelet therapy with prasugrel in patients with diabetes mellitus in the trial to assess improvement in therapeutic outcomes by optimizing platelet inhibition with prasugrel-Thrombolysis in Myocardial Infarction 38. Circulation 2008;118(16): 1626-1636

53 James S, Angiolillo DJ, Cornel JH, et al; PLATO Study Group. Ticagrelor vs. clopidogrel in patients with acute coronary syndromes and diabetes: a substudy from the PLATelet inhibition and patient Outcomes (PLATO) trial. Eur Heart J 2010;31(24):3006-3016 